\title{
Klinefelter en fertiliteit
}

\author{
Kathleen W. M. D'Hauwers' ${ }^{1}$
}

Published online: 6 November 2018

(c) The Author(s) 2018

\section{Samenvatting}

Een deel van de mannen met Klinefelter-syndroom (KS) heeft focale spermatogenese. De zaadcellen kunnen zich in het ejaculaat bevinden $(8 \%)$ of kunnen middels TESE $(50 \%)$ geoogst en gecryopreserveerd worden. Kernvraag is wanneer het fertiliteitsonderzoek ingezet moet worden. Semenanalyse is de eerste stap. TESE wordt niet voor de leeftijd van 16 jaar uitgevoerd: de kans bestaat dat immature geslachtscellen, die mogelijk op latere leeftijd nog kunnen ontwikkelen tot zaadcellen, verwijderd worden. Advies is om de jongen met KS en zijn ouders goed te counselen over de mogelijkheden en beperkingen van fertiliteitspreservatie. De vroegste leeftijd om TESE uit te voeren, is in principe 18 jaar, waarbij in acht moet worden genomen dat de spermatogenese in de loop der jaren zal afnemen. Of de bovengrens voor spermatogenese bij KS 25 jaar is, dan wel 39 jaar, is onderwerp van onderzoek. Het cryopreserveren van spermatogene stamcellen is verlaten, omdat daarvoor bij deze jongens geen geschikte toepassingen zijn.

Trefwoorden Klinefelter-syndroom $\cdot$ vruchtbaarheid $\cdot$ zaadcel $\cdot$ TESE $\cdot$ testosteron $\cdot$ adolescent $\cdot$ volwassene

\section{Klinefelter and fertility}

\begin{abstract}
Part of individuals with KS still have focal spermatogenesis. Spermatozoa can be found in ejaculates (8\%) or in TESE $(50 \%)$. Major question is when to start the quest for spermatozoa. When there is an azoospermia, TESE is the next step. It is advised not to perform TESE before 16 years of age: immature germ cells, that might possibly develop into spermatozoa after puberty, are permanently removed by TESE. Young men with KS and their parents need to be counseled about the possibilities and limitations of fertility-preservation. When thinking of TESE, we have to keep in mind that spermatogenesis decreases with age. If spermatogenesis is limited by the age of 25 , or by the age of 39, is still subject to debate. Fertility preserving approach such as cryopreservation of spermatogonial stem cells is abandoned because these technique cannot be used in a therapeutic way in men with $\mathrm{KS}$.
\end{abstract}

Keywords Klinefelter syndrome $\cdot$ fertility $\cdot$ spermatozoa $\cdot$ TESE $\cdot$ testosterone $\cdot$ adolescent $\cdot$ adult

\section{Introductie}

Ongeveer 1 op 600-700 mannen in de algemene bevolking heeft het syndroom van Klinefelter (KS) [1]. Het syndroom werd voor het eerst beschreven door Harry F. Klinefelter in 1942 [2]: 'A syndrome characterized by gynecomastia, aspermatogenesis, and increased excretion of follicle-stimu-

Kathleen W. M. D'Hauwers, MD PhD

kathleen.dhauwers@ radboudumc.nl

1 Afdeling Andrologie, Radboud Universiteit Nijmegen, Nijmegen, Nederland lating hormone .... Het karyotype werd onthuld door Patricia Jacobs in 1959 [3].

Mannen met KS hebben één of meer X-chromosomen te veel in het genoom van alle of bijna alle lichaamscellen. In $90 \%$ van de gevallen betreft het $47, X X Y$. De overige $10 \%$ zijn mozaïek karyotypes (met name 46,XY/47,XXY) of karyotypes met een hogere aneuploïdie, 48,XXXY of zelfs 49,XXXXY [2, 4-6].

Het extra X-chromosoom is in iets meer dan de helft van de gevallen het gevolg van nondisjunctie in de meiose I of II in de eicel en in iets minder dan de helft van meiose Inondisjunctie in de zaadcel. 
Typische kenmerken van KS zijn: (a) gynaecomastie en een laag testosterongehalte, waardoor er sprake is van een verminderd libido, minder energie en minder spierkracht; (b) kleine testes en infertiliteit door het disfunctioneren van Sertoli-cellen en (c) psychosociale problemen, waaronder moeite met concentratie en studie.

Hoe hoger de aneuploïde, hoe meer uitgesproken het fenotype: met name grotere leer-/spraak-/taalmoeilijkheden, meer faciale anomalieën en skeletafwijkingen [5]. Het fenotype bij KS is echter erg divers, waardoor symptomen ook minimaal aanwezig kunnen zijn. Om die reden wordt KS niet altijd ontdekt: de inschatting is dat ongeveer $75 \%$ van de mannen met KS hun diagnose niet weet [1].

Globaal genomen zijn er drie momenten waarop de diagnose gesteld wordt: prenataal tijdens de vruchtwaterpunctie, op jonge leeftijd indien eraan gedacht wordt bij gedrags-, leer- en geheugenproblemen en op volwassen leeftijd als de kinderwens onvervuld blijft.

\section{KS en vruchtbaarheid}

KS is de meest voorkomende oorzaak van infertiliteit: $10-15 \%$ van de mannen met azoöspermie krijgt de diagnose KS [7, 8]. Van de volwassen mannen met KS heeft $90 \%$ een non-obstructieve azoöspermie (NOA) en $10 \%$ een oligospermie [9]. Met behulp van intracytoplasmatische sperma-injectie (ICSI) kunnen deze mannen een genetisch eigen kind krijgen.

De kans op een levend geboren kind na TESE-ICSI bij mannen met KS is $28 \%$, wat vergelijkbaar is met de kans (26\%) bij mannen met NOA [10]. De kans op een kindje met een chromosoom te veel of te weinig bedraagt $1 \%$, net zoals bij kinderen van NOA-mannen zonder KS.

De herhalingskans bij een volgende zwangerschap voor ouders die een zoon met KS hebben, is minder dan $1 \%$.

\section{KS en spermatogenese}

Tijdens de puberteit ondergaan de testes van de jongen met KS veranderingen: afbraak van stamcellen, hyalinisatie van tubuli, degeneratie van Sertoli-cellen en hyperplasie van Leydig-cellen [11]: Hierdoor stopt de spermatogenese. De reden dat dit gebeurt en wat de exacte invloed is van het extra X-chromosoom, is onbekend.

Sommige jongens met KS behouden wel focale spermatogenese.

\section{Histologie}

We weten niet of de embryonale stamcelontwikkeling normaal verloopt. Er zijn zowel studies die normale histologie beschrijven in foetale testes (case-reports; [12, 13]), als studies die reeds afbraak van stamcellen beschrijven in een vroeg embryonaal stadium [14] en in een mid-embryonaal stadium [15], met een verder normale opbouw van Sertolien Leydig-cellen. Op kinderleeftijd kan er nog een redelijk normale histologie worden waargenomen, maar met het toenemen van de leeftijd treedt graduele degeneratie op en tijdens de vroege puberteit zet de celdood van de spermatogoniën in $[11,16]$. Mogelijk is dit het gevolg van intratesticulaire hormonale disbalans, Sertoli-celdisfunctie of defecte spermatogene stamcelvernieuwing [17].

\section{Hormonaal}

Gedurende de eerste zes maanden ondergaan baby's zonder KS een minipuberteit, waarbij er sterk verhoogde waarden zijn van follikelstimulerend hormoon (FSH), luteïniserend hormoon (LH), inhibine B en testosteron [18]. Ook baby's met KS doorlopen hormonaal gezien een minipuberteit, maar het gehalte aan testosteron is significant lager in vergelijking met baby's met een normaal karyotype [19]. Dit zou te wijten zijn aan een verstoorde functie van de Leydigcellen, hoewel deze cellen zich wel normaal ontwikkelen. Tijdens de prepuberteit zijn de hormonale waarden (testosteron, sekshormoonbindend globuline (SHBG), FSH, LH, inhibine B, anti-Müller-hormoon (AMH) en estradiol) normaal, maar is het aantal spermatogoniën verminderd [20]. De start van de celdood van spermatogoniën correspondeert met een toename van FSH tijdens de puberteit.

\section{KS en sperm retrieval rate}

\section{Adolescenten}

Tab. 1 toont een overzicht van studies naar de sperm retrieval rate (SSR) in ejaculaat en TESE bij adolescenten met KS [21-29]. De SRR's variëren in de verschillende studies van 0-70\%, ongeacht of het mozaïek of non-mozaïek KS betreft. De SRR van $70 \%$ werd behaald in de studie van Mehta et al. waarin 10 adolescenten met non-mozaïekKS voorbehandeld werden met testosteron en letrozol, een aromatase-inhibitor [26].

\section{Volwassenen}

De review uit 2013 van Aksglaede en Juul toonde aan dat ongeveer $8 \%$ van de volwassen mannen met KS zaadcellen in het ejaculaat heeft en dat $50 \%$ zaadcellen heeft in het TESE-materiaal [30].

Zie tab. 2. 
Tabel 1 Aanwezigheid van spermatozoa in ejaculaat of TESE, bij adolescenten en jongvolwassenen met KS

\begin{tabular}{|c|c|c|c|c|}
\hline Studie/referentie & $\begin{array}{l}\text { aantal } \\
\text { deel- } \\
\text { ne- } \\
\text { mers }\end{array}$ & leeftijd & methode & resultaten spermatozoa $(\%)$ \\
\hline Damani et al., 2001 [21] & 1 & 15 & TESE & $1 / 1(100)$ \\
\hline Wilkström et al., 2004 [11] & 14 & $10-14$ & TESE & $\begin{array}{l}0 / 14(0) \\
7 / 14(50) \text { spermatogonia }\end{array}$ \\
\hline Aksglaede et al., 2008 [22] & 12 & $15-20$ & ejaculaat & $0 / 12(0)$ \\
\hline Gies et al., 2012 [23] & 7 & $10-16$ & ejaculaat & $0 / 7(0)$ \\
\hline Van Saen et al., 2012 [24] & & & TESE & $\begin{array}{l}0 / 7(0) \\
5 / 7(72) \text { spermatogonia }\end{array}$ \\
\hline Rives et al., 2013 [25] & 5 & $15-17$ & TESE & 2/5 (40) spermatozoa/spermatids \\
\hline Metha et al., 2013 [26] & 10 & $14-22$ & TESE & $\begin{array}{l}7 / 10(70) \text {, na voorbehandeling met } \\
\text { letrozole }\end{array}$ \\
\hline Plotton et al., 2015 [27] & 21 & $15-20$ & TESE & $12 / 21(57)$ \\
\hline Rohayem et al., 2016 [28] & 50 & $13-19$ & $\begin{array}{l}\text { ejaculaat } \\
\text { mTESE }\end{array}$ & $\begin{array}{c}1 / 28(4) \\
19 / 50(38)\end{array}$ \\
\hline Nahata et al., 2016 [29] & 15 & $12-25$ & $\begin{array}{l}\text { ejaculaat } \\
\text { mTESE }\end{array}$ & $\begin{array}{l}0 / 15(0) \\
5 / 10(50)\end{array}$ \\
\hline Totaal & 135 & $10-25$ & $\begin{array}{l}\text { ejaculaat } \\
(\mathrm{m}) \mathrm{TESE} \\
(\mathrm{m}) \mathrm{TESE}\end{array}$ & $\begin{array}{l}1 / 62(2) \\
46 / 118(39) \\
12 / 21(57) \text { spermatogonia }\end{array}$ \\
\hline
\end{tabular}

\section{KS en stamcellen}

Prepuberale jongens die een gonadotoxische behandeling moeten ondergaan, kunnen vóór hun behandeling een testisbiopt laten uitvoeren. Aangetroffen stamcellen worden ingevroren. Op het moment dat de jongens op volwassen leeftijd een kinderwens hebben, worden de stamcellen in vitro vermeerderd en vervolgens geïnjecteerd in de testes. Deze procedure verloopt in experimentele setting: mogelijk zullen op niet al te lange termijn de eerste volwassenen hun fertiliteitsbehandeling mogen starten.

Het preventief afnemen en cryopreserveren van spermatogene stamcellen bij jongens met KS is verlaten. Stamcellen worden in ongeveer $50 \%$ van de testisbiopten van adolescenten met KS aangetroffen. Echter, bij KS treedt er vanaf de puberteit een onomkeerbare atrofie van het testisweefsel op, waardoor de stamcellen geen niche hebben om hun effect uit te oefenen. Daarbij bestaat de kans dat door dit biopt vroegtijdig af te nemen, de enige stamcellen die in de puberteit zouden kunnen ontwikkelen tot zaadcellen, verwijderd worden.

\section{De praktijk}

\section{Fertiliteitspreservatie}

Bij sommige individuen met $\mathrm{KS}$ is er focale spermatogenese, zodat semencryopreservatie uit het ejaculaat of uit TESE-materiaal mogelijk is. De uitdaging is om het meest geschikte tijdstip te vinden om op zoek te gaan naar zaadcellen. Er zijn geen voorspellende factoren die dit moment aangeven. Rohayem et al. toonden wel aan dat de kans op het aantreffen van zaadcellen bij mannen met KS groter is bij een testosteronwaarde $>7,5 \mathrm{nmol} / 1$ en een $\mathrm{LH}$-waarde $<17 \mathrm{U} / 1$ [28].

Oplopende leeftijd lijkt een beperkende factor voor succesvolle TESE bij mannen met KS [31, 32], vandaar het advies fertiliteitspreservatie bij voorkeur te verrichten voor het $25^{\mathrm{e}}$ levensjaar. Tegenstrijdige resultaten komen uit een Amerikaanse hoogvolume-TESE-kliniek, waar succesvolle TESE bij mannen met KS wordt beschreven tot 35 jaar en ouder, alhoewel de SRR significant hoger was bij patiënten jonger dan 35 jaar [33]. Een recente studie van Plotton et al. rapporteerde geen verschil in SRR tussen 25 mannen met KS tussen 15 en 23 jaar en 16 mannen met KS tussen 25 en 39 jaar oud [27].

Dit kan erop wijzen dat zich bij KS twee situaties voordoen. De situatie dat er geen spermatogenese is, en de situatie dat die er wel is, en behouden blijft, tot de leeftijd van ongeveer eind 30. Met andere woorden, de mannen die als twintiger een succesvolle TESE hebben, zijn dezelfde mannen die ook een succesvolle TESE zouden hebben als dertiger. Naar deze stelling is verder onderzoek nodig.

Het wordt aanbevolen om vanaf de leeftijd van 12-13 jaar de vruchtbaarheidsproblemen die inherent zijn aan de diagnose KS, en de eventuele therapeutische mogelijkheden en beperkingen, te bespreken met de patiënt en zijn ouders/begeleiders. Er zijn twee mogelijkheden: op jongvolwassen leeftijd een preventieve semenanalyse en/of TESE 
Tabel 2 Overzicht opbrengst TESE bij volwassenen

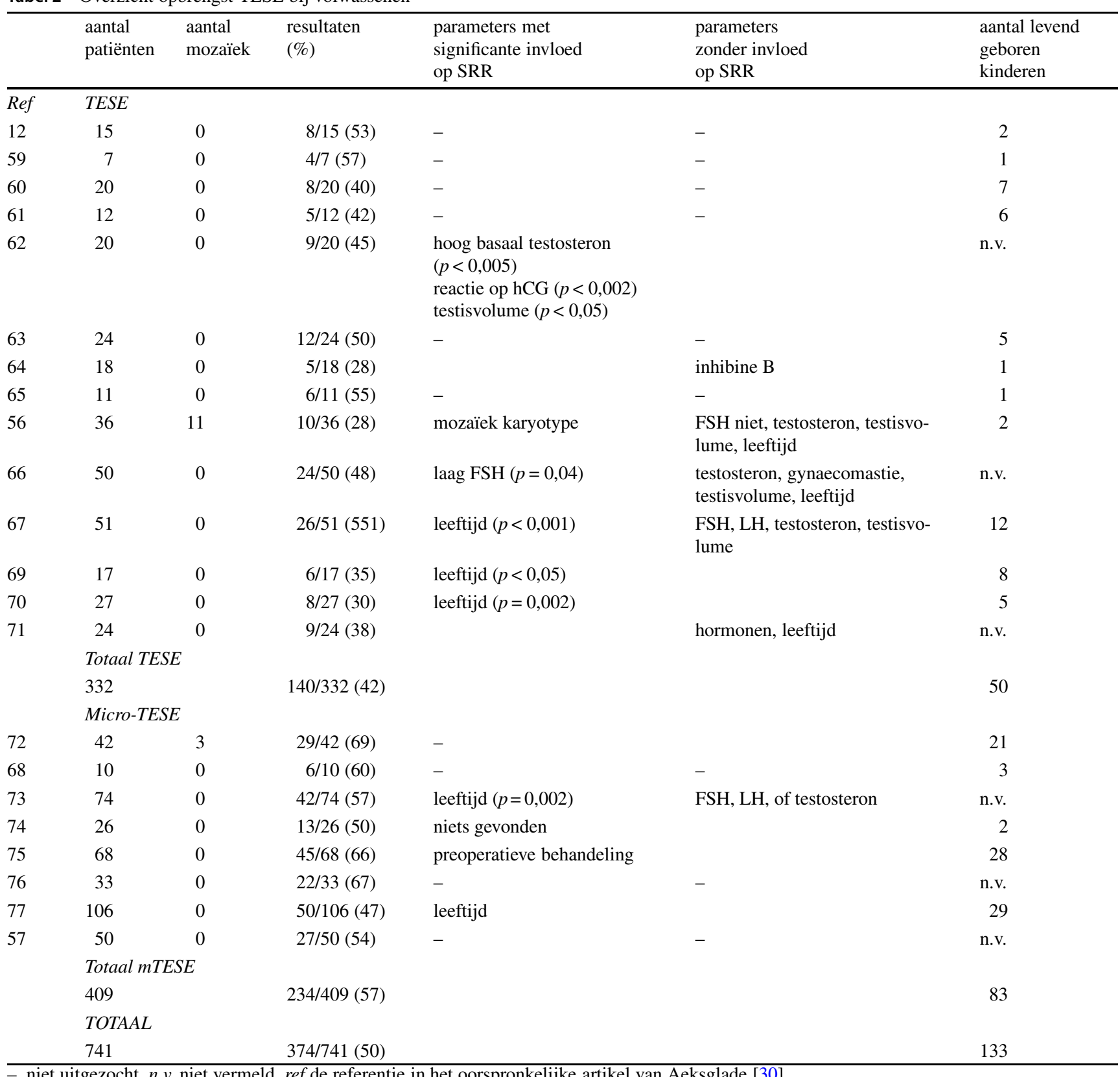

- niet uitgezocht, $n . v$. niet vermeld, $r$ f de referentie in het oorspronkelijke artikel van Aeksglade [30]

uitvoeren, of deze uitstellen tot de volwassen leeftijd, op het moment dat er sprake is van een actieve kinderwens.

Momenteel wordt in ieder geval gewacht tot er voldoende seksuele rijping is (Tanner stadium 3 ) en de jongen vertrouwd is met masturbatie. Gemiddeld negen maanden na de eerste masturbatie ontstaat er ook een lozing. Het vroegste moment om op zoek te gaan naar zaadcellen is 18 jaar. Op die leeftijd heeft de jongvolwassene enige levenservaring en is hij wilsbekwaam. Het aanbieden van een semenanalyse en TESE aan jonge pubers $(<16$ jaar) is verlaten [34].
Gies et al. toonden aan de jongens met KS zelf minder aandacht hebben voor het veilig stellen van hun zaadcellen en dat de vraag rond vruchtbaarheid hen over het algemeen weinig zorgen baart, terwijl het voor de ouders een belangrijk punt van aandacht is [35].

\section{Fertiliteitspreservatie en voorbehandelen}

Observationele studies waarbij mannen met KS worden voorbehandeld met aromataseremmers of humaan choriongonadotrofine (HCG) gedurende 3-6 maanden voorafgaande aan een TESE, laten een SRR tot $77 \%$ zien [33]. 
Sommige auteurs gebruiken deze behandeling standaard bij mannen met serum-testosteronwaarden $<8 \mathrm{nmol} / 1[17,26]$. Omdat het effect van voorbehandeling niet gerandomiseerd is uitgezocht, wordt hiervoor geen aanbeveling gedaan.

\section{Fertiliteitspreservatie en testosteron}

Testosteron onderdrukt de spermatogenese. Een recente studie onder 41 adolescenten en volwassenen met non-mozaïek KS toont aan dat dit effect reversibel is. Er werd geen significant verschil in SRR bij TESE aangetoond tussen 17 mannen die zes maanden tevoren testosteronsuppletie staakten en 24 patiënten die nooit suppletie ontvingen $(52,9 \%$ vs. 59,1\%) [27]. De reversibele relatie tussen testosteronsuppletie en spermatogenese moet besproken worden vóór de aanvang van androgeensubstitutie. Indien het starten van testosteronsuppletie in de puberteit noodzakelijk is, kan de TESE later worden uitgevoerd. Bij volwassen mannen met KS dienen semencryopreservatie, indien mogelijk, en TESE, indien nodig, overwogen en uitgevoerd worden vóór aanvang van de testosteronsuppletie.

\section{Conclusies}

- Sommige mannen met KS hebben focale spermatogenese.

- Het wordt geadviseerd om de jongen met KS en zijn ouders/begeleiders vanaf de puberteit te counselen over de mogelijkheden en beperkingen betreffende fertiliteitspreservatie.

- Er zijn geen voorspellende factoren op grond waarvan het meest ideale moment van fertiliteitsonderzoek kan worden bepaald.

- Het wordt geadviseerd om geen fertiliteitstraject (ejaculatie of TESE) in te zetten voor het 18e levensjaar.

- Het wordt geadviseerd om altijd te starten met semenanalyse.

- In gerandomiseerde studies is tot nu toe niet bewezen dat medicamenteuze voorbehandeling leidt tot verhoging van de SRR.

- Het wordt geadviseerd om testosteronbehandeling minimaal 3-6 maanden voorafgaand aan het fertiliteitstraject te staken.

- Het chirurgisch verkrijgen van spermatogene stamcellen bij KS is verlaten.

- Er is geen verschil in SRR tussen KS-mannen met het mozaïek of het non-mozaïek karyotype.

Open Access This article is distributed under the terms of the Creative Commons Attribution 4.0 International License (http:// creativecommons.org/licenses/by/4.0/), which permits unrestricted use, distribution, and reproduction in any medium, provided you give appropriate credit to the original author(s) and the source, provide a link to the Creative Commons license, and indicate if changes were made.

\section{Literatuur}

1. Bojesen A, Juul S, Hojbjerg Gravholt C. Prenatal and postnatal prevalence of Klinefelter syndrome: a national registry study. J Clin Endocrinol Metab. 2003;88(2):622-6.

2. Klinefelter H, Reifenstein E, Albright F. Syndrome characterized by gynecomastia, aspermatogenesis without aleydigism, and increased excretion of follicle-stimulating hormone. J Clin Endocrinol Metab. 1942;2:615-27.

3. Jacobs P, Strong J. A case of human intersexuality having a possible XXY sex-determining mechanism. Nature. 1959;183:302-3.

4. Lanfranco F, Kamischke A, Zitzmann M, Nieschlag E. Klinefelter's syndrome. Lancet. 2004;364(9430):273-83.

5. Visootsak J, Graham JM. Klinefelter syndrome and other sex chromosomal aneuploidies. Orphanet J Rare Dis. 2006;1:42.

6. Linden MG, Bender BG, Robinson A. Sex chromosome tetrasomy and pentasomy. Pediatrics. 1995;96:672-82.

7. Palermo GD, Schlegel PN, Hariprashad JJ, Ergün B, Mielnik A, Zaninovic N, et al. Fertilization and pregnancy outcome with intracytoplasmic sperm injection for azoospermic men. Hum Reprod. 1999;14(3):741-8.

8. Pina-Neto JM, Carrara RC, Bisinella R, Mazzucatto LF, Martins MD, Sartoratto E, et al. Somatic cytogenetic and azoospermia factor gene microdeletion studies in infertile men. Braz J Med Biol Res. 2006;39(4):555-61.

9. Forti G, Corona G, Vignozzi L, Krausz C, Maggi M. Klinefelter's syndrome: a clinical and therapeutical update. Sexual development : genetics, molecular biology, evolution, endocrinology, embryology, and pathology of sex determination and differentiation. Sex Dev. 2010;4(4-5):249-58.

10. Yarali H, Polat M, Bozdag G, Gunel M, Alpas I, Esinler I, et al. TESE-ICSI in patients with non-mosaic Klinefelter syndrome: a comparative study. Reprod Biomed Online. 2009;18(6):756-60.

11. Wikström AM, Raivio T, Hadziselimovic F, Wikstroöm S, Tuuri T, Dunkel L. Klinefelter syndrome in adolescence: onset of puberty is associated with accelerated germ cell depletion. J Clin Endocrinol Metab. 2004;89(5):2263-70.

12. Flannery DB, Brown JA, Redwine FO, Winter P, Nance WE. Antenatally detected Klinefelter's syndrome in twins. Acta Genet Med Gemellol (Roma). 1984;33(1):51-6.

13. Gustavson KH, Kjessler B, Thoren S. Prenatal diagnosis of an XXY foetal karyotype in a woman with a previous 21 -trisomic child. Clin Genet. 1978;13(6):477-80.

14. Murken JD, Stengel-Rutkowski S, Walther JU, Westenfelder SR, Remberger KH, Zimmer F. Klinefelter's syndrome in a fetus. Lancet. 1974;2(7873): 171.

15. Coerdt W, Rehder H, Gausmann I, et al. Quantitative histology of human fetal testes in chromosomal disease. Pediatr Pathol. 1985;3(2-4):245-59.

16. Aksglaede L, Skakkebaek NE, Almstrup K, Juul A. Clinical and biological parameters in 166 boys, adolescents and adults with nonmosaic klinefelter syndrome: a copenhagen experience. Acta Paediatr. 2011;100(6):793-806.

17. Paduch DA, Bolyakov A, Cohen P, Travis A. Reproduction in men with klinefelter syndrome: the past, the present, and the future. Semin Reprod Med. 2009;27(2):137-48.

18. Andersson AM, Toppari J, Haavisto AM, Petersen JHm Simell T, Simell O, et al. Longitudinal reproductive hormone profiles in infants: pea of inhibin B levels in infant boys exceeds levels in adult men. J Clin Endocrinol Metab. 1998;83:675-81.

19. Lahlou N, Fennoy I, Carel JC, Roger M. Inhibin B and anti-Müllerian hormone, but not testosterone levels, are normal in infants 
with nonmosaic Klinefelter syndrome. J Clin Endocrinol Metab. 2004;89(4):1864-8.

20. Bastida MG, Rey RA, Bergada I, Bedecarrás P, Andreone L, Rey $\mathrm{G}$ del, et al. Establishment of testicular endocrine function impairment during childhood and puberty in boys with Klinefelter syndrome. J Clin Endocrinol Metab. 2007;67(6):863-70.

21. Damani MN, Mittal R, Oates RD. Testicular tissue extraction in a young male with 47,XXY Klinefelter's syndrome: potential strategy for preservation of fertility. Fertil Steril. 2001;76(5):1054-6.

22. Aksglaede L, Jørgensen N, Skakkebaek NE, Juul A. Low semen volume in 47 adolescents and adults with 47,XXY Klinefelter or 46,XX male syndrome. Int J Androl. 2008;32(4):376-84.

23. Gies I, Schepper JD, Saen DV, Anckaert E, Goossens E, Tournaye $\mathrm{H}$. Failure of a combined clinical- and hormonal-based strategy to detect early spermatogenesis and retrieve spermatogonial stem cells in $47, \mathrm{XXY}$ boys by single testicular biopsy. Hum Reprod. 2012;27(4):998-1004.

24. Van Saen D, Tournaye H, Goossens E. Presence of spermatognonia in 47,XXY men with no spermatozoa recovered after testicular sperm extraction. Fertil Steril. 2012b;97:319-23.

25. Rives N, Milazzo JP, Perdrix A, Castanet M, Joly-Hélas G, Silbert L, et al. The feasibility of fertility preservation in adolescents with Klinefelter syndrome. Hum Reprod. 2013;28(6):1468-79.

26. Mehta A, Bolyakov A, Roosma J, Schlegel PN, Paduch DA. Successful testicular sperm retrieval in adolescents with Klinefelter syndrome treated with at least 1 year of topical testosterone and aromatase inhibitor. Fertil Steril. 2013;100:970-4.

27. Plotton I, Giscard d'Estaing S, Cuzin B, Brosse A, Benchaib M, Lornage $\mathrm{J}$, et al. Preliminary results of a prospective study of testicular sperm extraction in young versus adult patients with Nonmosaic 47,XXY Klinefelter syndrome. J Clin Endocrinol Metab. 2015;100(3):961967.
28. Rohayem J, Fricke R, Czeloth K, Malidis C, Wistuba J, Krallmann C, et al. Age and markers of Leydig cell function, but not of Sertoli cell function predict the success of sperm retrieval in adolescents and adults with Klinefelter's syndrome. Andrology. 2015;3(5):868-75.

29. Nahata L, Yu RN, Paltiel HJ, Chow JS, Logvinenko T, Rosoklija I, Cohen LE. Sperm retrieval in adolescents and young adults with Klinefelter syndrome: a prospective, pilot study. J Pediatr. 2016;170:260-5.

30. Aksglaede L, Juul A. Therapy of endocrine disease: Testicular function and fertility in men with Klinefelter syndrome: a review. Eur J Endocrinol. 2013;168(4):R67-76.

31. Emre Bakircioglu M, Erden HF, Kaplancan T, Ciray N, Bener F, Bahceci M. Aging may adversely affect testicular sperm recovery in patients with klinefelter syndrome. Urology. 2006;68(5):1082-6.

32. Okada H, Goda K, Yamamoto Y, Sofikitis N, Miyagawa I, Mio $\mathrm{Y}$, et al. Age as a limiting factor for successful sperm retrieval in patients with nonmosaic klinefelter's syndrome. Fertil Steril. 2005;84(6):1662-4.

33. Ramasamy R, Ricci JA, Palermo GD, Gosden LV, Rosenwaks Z, Schlegel PN. Successful fertility treatment for klinefelter's syndrome. J Urol. 2009;182(3):1108-13.

34. Franik S, Hoeijmakers Y, D'Hauwers K, Braat DD, Nelen WL, Smeets D, et al. Klinefelter syndrome and fertility: sperm preservation should not be offered to children with Klinefelter syndrome. Hum Reprod. 2016;31(9):1952-9.

35. Gies I, Tournaye H, De Schepper J. Attitudes of parents of Klinefelter boys and pediatricians towards neonatal screening and fertility preservation techniques in Klinefelter syndrome. Eur J Pediatr. 2016;175(3):399-404.

Kathleen W.M. D'Hauwers uroloog, androloog 